\title{
Entre a Terra e o corpo: a experiência da natureza na obra de Giuseppe Penone
}

\author{
Between Earth and the Body: The Experience of Nature \\ in the Work of Giuseppe Penone
}

\author{
Entre la Tierra y el cuerpo: la experiencia de la naturaleza \\ en el trabajo de Giuseppe Penone
}

Arthur Simões Caetano Cabral (Universidade Federal de Goiás, Brasil)*

https://doi.org/10.22409/poiesis.v22i37.44530

\begin{abstract}
RESUMO: O presente artigo procura discutir as possibilidades de experiência sensível da natureza suscitadas pelas obras de Giuseppe Penone. Entendida enquanto fenômeno estético, tal experiência pressupõe um contato direto entre o homem e a Terra. O espaço produzido nas obras de Penone, no qual torna-se possível esse contato, é aqui entendido como uma realidade sempre compartilhada, na qual sujeito e objeto confundem-se mutuamente. Nesse sentido, a produção de Penone situa-se a meio caminho entre a Terra - cuja materialidade é, a um só tempo, tema e suporte de expressões artísticas - e o corpo que a esculpe, a decalca, a imagina, a sonha, a experimenta.
\end{abstract}

PALAVRAS-CHAVE: arte e natureza; experiência sensível; imaginação da matéria; Giuseppe Penone

\footnotetext{
* Arthur Simões Caetano Cabral é doutor em Arquitetura e Urbanismo pela Universidade de São Paulo e professor do curso de Arquitetura e Urbanismo da Universidade Federal de Goiás. Orcid: https://orcid.org/0000-0002-2921-4374. E-mail: arthur.cabral@ufg.br.
} 
ABSTRACT: This paper discusses the possibilities of sensitive experience of nature raised by the works of Giuseppe Penone. Understood as an aesthetic phenomenon, such experience presupposes a direct contact between the man and the Earth. The space produced in Penone's works, in which this contact is possible, is here understood as a reality that is always shared, in which subject and object are mutually confused. In this sense, Penone's production is located halfway between the Earth - whose materiality is, at the same time, the theme and support of artistic expressions - and the body that sculpt, decal, imagine, dream, experiment.

KEYWORDS: art and nature; sensitive experience; material imagination; Giuseppe Penone

RESUMEN: Este artículo analiza las posibilidades de experiencia sensible de la naturaleza planteada por las obras de Giuseppe Penone. Entendida como un fenómeno estético, tal experiencia presupone el contacto directo entre el hombre y la Tierra. El espacio producido en las obras de Penone, en el que este contacto es posible, se entiende aquí como una realidad que siempre se comparte, en la que sujeto y objeto se confunden mutuamente. En este sentido, la producción de Penone se encuentra a medio camino entre la Tierra, cuya materialidad es, al mismo tiempo, el tema y el soporte de expresiones artísticas, y el cuerpo que esculpe, calcomanía, imagina, sueña y experimenta.

PALABRAS CLAVE: arte y naturaleza; experiencia sensible; imaginación de la materia; Giuseppe Penone

Recebido: 11/8/2020; Aprovado: 7/12/2020; Publicado: 2/1/2021.

Citação recomendada:

CABRAL, Arthur Simões Caetano. Entre a Terra e o corpo: a experiência da natureza na obra de Giuseppe Penone. Revista Poiésis, Niterói, v. 22, n. 37, p. 301-330, jan./jun. 2021. [https://doi.org/10.22409/poiesis.v22i37.44530]

\section{(cc) BY-NC-ND}

Este documento é distribuído nos termos da licença Creative Commons Atribuição-NãoComercial 4.0 Internacional (CC-BY-NC) (c) 2021 Arthur Simões Caetano Cabral 


\section{Entre a Terra e o corpo: a experiência da natureza na obra de Giuseppe Penone}

Introdução

No fim dos anos 1960, as ações de diversos artistas americanos e europeus voltaram-se para além do campo produtivo da sociedade industrial e para além do espaço urbano. Considerando as grandes cidades contemporâneas e seus mais diversos artifícios como expressões do domínio técnico do mundo, a land art e arte povera procuraram remontar, em grande medida, à ancestralidade da obra humana. A experiência dos landartistas, de maneira geral, visava restituir à arte $o$ instante do gesto a partir do qual ela tem origem, o evento que assinala a passagem da matéria desde sua condição natural ao mundo humano. Ações e ritos que remontavam a visões míticas do mundo, a contrapelo dos processos econômicos e culturais ocidentais contemporâneos, constavam dos experimentos desses artistas. $\mathrm{O}$ modo como o homem se reporta à natureza, percebendo a si próprio como ser estranho a ela, de maneira geral, pode ser entendido como uma das questões centrais da produção artística desse período. 
A concretização e a atribuição de formas sensíveis às categorias do espaço e do tempo, segundo Gilles Tiberghien (2005), são colocadas em jogo pela land art. A partir do reconhecimento de certos territórios, muitas vezes inóspitos ou apartados de quaisquer assentamentos humanos, diferentes procedimentos eram adotados para que se imprimissem marcas sobre eles. Seja em manifestações totêmicas, mediante a colocação de grandes rochas ou de movimentações colossais de terra, seja com a demarcação sutil de linhas efêmeras sobre certo campo, entre tantas outras abordagens, muitas das experimentações artísticas dos anos 1960 se voltavam à paisagem. Na condição de marcas inscritas sobre o terreno, essas obras eram deixadas ao tempo, podendo fundir-se a elementos naturais preexistentes, modificar-se ou até mesmo desaparecer com o passar dos anos. Trata-se de uma produção artística que considera o tempo tanto em seus ritmos proporcionais à condição humana - o tempo do processo de elaboração e o tempo de experiência sensível das obras - como também o tempo incomensurável da natureza, aspecto pelo qual é possível reafirmar o for- te parentesco entre a land art e a paisagem $^{1}$.

Considerando os nexos estabelecidos entre as noções de paisagem e arte, este artigo propõe a análise de obras do artista italiano Giuseppe Penone, realizadas no decorrer das últimas décadas do século $\mathrm{XX}$, com vistas à detecção dos modos pelos quais a poética dessas obras permite que venham à tona experiências sensíveis da natureza. As obras de Penone, de maneira geral, remontam à ancestralidade da relação entre o homem e a Terra, na medida em que, mediante gestos escultóricos muito simples (tais como segurar com a mão o ramo de uma árvore, como se fosse possível interferir em seu crescimento, ou fechar a mandíbula para que se molde, com o negativo da boca, uma porção de massa plástica), correspondem à inauguração de um mundo humano a partir da interação com uma natureza que sempre se fecha, que nunca se revela por completo. Com efeito, Penone (2012) afirma que um dos interesses centrais de sua arte é estabelecer equivalências entre a força de seu gesto e as forças da natureza. 
É possível depreender, a partir de uma visão geral de sua obra, que a natureza comparece para Penone não apenas como uma força de resistência, como uma matéria dura ou mole cujo embate com suas mãos dá origem à obra, mas também como uma força criadora, uma potência pregnante de espaços, de formas, de esculturas. Como será visto adiante, o modo como Penone aborda a relação entre seu corpo e a Terra, descobrindo na natureza a medida de suas próprias forças, anima um conjunto de imagens poéticas (BACHELARD, 2008) referentes ao espaço, à vontade de manuseio da matéria, ao deixar-se levar pelas águas cristalinas de um pequeno riacho, aos sonhos de repouso nos abrigos mais ancestrais. A imaginação material fortemente trabalhada nas obras de Penone é aqui entendida como uma condição fundamental do contato entre o homem e a Terra - no mesmo instante em que apreendemos algo, esteticamente começamos a imaginar, produzimos imagens - e que em muito contribui, assim, para a experiência sensível da natureza.

\section{Afinidades possíveis entre natureza, arte e paisagem}

Antes de prosseguirmos com a análise das obras de Giuseppe Penone, cabe tecermos breves considerações acerca dos modos pelos quais nos relacionamos com a natureza. Segundo reflexões do poeta Rainer Maria Rilke, a relação que estabelecemos com a Terra desde o princípio de nossa existência é sempre unilateral: a natureza nada sabe de nós, de nada interessa a ela se a cultivamos ou se nos servimos de parte de suas forças e de maneira alguma ela compartilha dos sentimentos humanos. Há um enorme estranhamento sentido pelo homem diante da natureza, o que permite ao poeta afirmar que "sozinhos, na companhia de um cadáver, não estaríamos tão abandonados como quando sozinhos no meio das árvores" (RILKE, 2009, p. 60). Diante disso, Rilke compreende a resignação de alguns homens que passam a dividir, em sociedade, o mesmo trabalho e o mesmo destino, "enquanto outros, aqueles que não querem deixar a natureza perdida, seguem suas pegadas buscando, agora conscientemente e com vontade determinada, aproximar-se novamente dela do modo como, sem que 
soubessem, dela eram próximos na infância" (RILKE, 2009, p. 62). O poeta alemão esclarece que esses últimos são os artistas - poetas ou pintores, compositores ou arquitetos - que, em sua profunda solidão, preferem o eterno da natureza ao efêmero da humanidade.

Ao se voltarem à natureza, esses homens, os artistas, voltam-se àquilo que é governado por leis profundas, abdicando dos fatos que ocorrem casualmente. Rilke pondera que, na impossibilidade de convencer a natureza a participar de sua dor ou de compartilhar com ela sua alegria, esses homens "reconhecem como seu dever compreendê-la, de modo a poder encontrar, em alguma parte da sua ordem grandiosa, um lugar seu" (RILKE, 2009, p. 62). É graças a esses indivíduos solitários que toda a existência humana se aproxima da natureza. Vale considerar, assim, a imaginação poeticamente trabalhada da natureza para que nos reaproximemos de sua existência sempre misteriosa, sempre estranha para nós.

Será que o maior e talvez o mais singular valor da arte não estaria nela ser 0 meio pelo qual 0 homem e a paisagem, 0 mundo e a forma, se encontram? Na realidade eles vivem lado a la-

do, quase que se ignorando mutuamente, $e$ num quadro, num edifício, numa sinfonia numa palavra, na arte - parecem unir-se, por assim dizer, numa verdade mais elevada e profética, como se respondessem a um recíproco apelo, e é como se mutuamente se completassem numa perfeita unidade que a essência da obra de arte revela. (RILKE, 2009, p. 62)

Ante todo o estranhamento que sentimos, em nossa condição humana, diante da natureza, diante de sua dimensão temporal incomensurável, diante de sua aparente indiferença em relação aos nossos sentimentos, a arte permite restabelecer a unidade entre o homem e a Terra. Para que se possa abrir na natureza o espaço da paisagem, ou seja, para que se estabeleça pela arte um sentimento estético em relação à natureza, o filósofo Gianni Carchia afirma que caberá ao artista "aprender a falar a língua da natureza, e a aula na qual ele deverá receber tal ensinamento não poderá ser senão a própria natureza livre: bosques, $[\ldots]$, montanhas, rios, vales, cuja forma e cujas cores ele deverá estudar incessantemente, por toda a vida" (CARCHIA, 2009, p. 211). 
A propósito da representação da paisagem na arte, sobretudo no tocante à pintura de paisagem, Carchia afirma que o artista deve proteger no espetáculo da natureza seu enigma, que deverá transformar em admiração seu próprio estupor ante a natureza (CARCHIA, 2009, p. 212). A paisagem, para ele, não é uma projeção da subjetividade de quem a admira ou a representa, nem tampouco o retorno, em imagem, de uma natureza definitivamente desencantada. Para os grandes artistas que se voltam à natureza, diz Carchia, a paisagem se coloca como a revelação de uma dimensão invisível através do aprofundamento de sua visibilidade (CARCHIA, 2009 , p. 211). Para que a arte consiga esse aprofundamento, para que o artista seja, de fato, íntimo da linguagem da natureza, é preciso preservar

\footnotetext{
[...] a capacidade de desconcertar-se, de maravilhar-se, de ver a natureza como uma intencionalidade que não está voltada ao nosso serviço, como uma finalidade sem fim. Não nos será possível, porém, ter acesso a esta compreensão se antes não exercitarmos esta ascese nos confrontos com a nossa vontade de domínio, se, portanto, não estivermos abertos àquele "mistério", àquele "invisível" que só a
}

visão da paisagem pode nos dar. (CARCHIA, 2009, p. 211)

É da intimidade entre o artista e a natureza, justamente, que se origina a obra de Giuseppe Penone. Sua arte é, ao mesmo tempo, telúrica e etérea; firmemente enraizada e, ao mesmo tempo, suscetível ao mais leve sopro. Trabalhando em um contexto em que os limites do campo da escultura expandiam-se (KRAUSS, 1978), Penone intervém no espaço a partir da essencialidade da capacidade sensorial humana: a visão, o tato, a audição confundem-se em um sentir que integra todo o corpo. Nas obras de Penone, os aromas pertencem tanto aos materiais que os exalam quanto ao olfato de quem os sente (MARANIELLO, 2009, p. 8), as superfícies moldadas, amassadas, desbastadas pertencem tanto à matéria trabalhada como à pele das mãos que tomam para si tal matéria. Sua arte coloca-se como a linha tênue onde se dá o encontro do homem com a Terra, onde se origina, a partir desse encontro, o mundo humano. Penone opera no horizonte de um agir que assume para si a impossibilidade de originar obras únicas e eternas. Pelo contrário, o interesse do artista se volta ao gesto primitivo do 
escultor que permite aderir a matéria ao corpo. Enquanto processo de uma arte que ganha autonomia pelo trabalho, pela energia despendida tanto pela matéria quanto por quem a trabalha, o fazer do escultor significa, para Penone, uma possibilidade de aproximação a um modo de agir potencialmente infinito, contínuo, replicado.

\section{Dissoluções mútuas de sujeito e objeto}

A partir da década de 1960, momento de redefinição de diversos paradigmas artísticos com a arte povera e a land art, Giuseppe Penone abandona a ideia de escultura em seu significado tradicional. Sua obra não consiste na elaboração de objetos passíveis de instalação sobre pedestais, por exemplo. A relação objetiva da escultura, isto é, a perspectiva convencional segundo a qual o fazer do escultor resultaria em um objeto tridimensional autônomo e independente de qualquer relação contextual, corpórea, espacial ou intersubjetiva, é deixada de lado na medida em que Penone utiliza gestos escultóricos quase atávicos para intervir no espaço, para experimentar o que decorre no espa- ço do contato entre seu corpo e elementos diversos da natureza. Trata-se de um trabalho fortemente ancorado no espaço, que assume como questões, justamente, os aspectos sensíveis do espaço, e que se sucede no decorrer do tempo. Suas obras têm uma duração própria, sendo mais ou menos efêmeras, e se desenvolvem ao longo do tempo. A ideia de tempo, contudo, parece sempre associar-se para Penone ao instante presente, seja no processo de elaboração das obras, seja em seu registro fotográfico ou em sua experiência direta: ao remeter a gestos humanos muito primitivos relacionados a um fazer escultórico, Penone não opera em uma dimensão de memória, e sim em uma dimensão arquetípica. Ele traz à tona, em um tempo que é sempre presente, a permanência de certos movimentos do corpo que são inerentes à condição humana desde o primeiro e imemorial contato do homem com a natureza.

Se a obra de Penone nasce do desejo de um contato paritário entre sua existência e as coisas do mundo, o simples fato de existirmos, de nos deslocarmos e de manusearmos a materialidade da Terra, alterando suas características, é entendido 
pelo artista como um modo de intervenção no espaço. É interessante observar nas obras e nos escritos de Penone, contudo, que não apenas a matéria manuseada se altera mediante o contato com as mãos, como também estas se alteram, recebendo para si as formas modeladas. Penone remonta, assim, às formas mais primitivas pelas quais o homem trabalha a Terra. Sua familiaridade e seu interesse em lidar com essas questões relacionam-se, em grande medida, com a experiência de sua juventude, vivida junto a bosques, riachos, afloramentos rochosos. Desde suas primeiras experimentações com as árvores, nas quais sua mão esculpida era posta agarrando partes de troncos, até suas obras mais recentes, conforme será apresentado a seguir, Penone parece levar aos limites sua intimidade com a natureza.

Essa intimidade pode ser vista em um trabalho de 1968, ocasião em que Giuseppe Penone elabora os primeiros esboços para uma espécie de banheira a ser imersa nas águas de um pequeno curso d'água (Fig. 1). Na margem dos croquis, o artista ressaltava entre suas anotações as dimensões que deveriam apresentar tal objeto e o local onde ele seria instalado: "A minha altura, o comprimento dos meus braços, a minha espessura em um riacho" (PENONE, 2009, p. 158, tradução nossa). Penone põe à disposição do escoar das águas aquilo que talvez seja o mais primitivo de sua existência, a materialidade de seu próprio corpo. O movimento do qual nasce o gesto escultórico é dado pelo fluxo do pequeno rio, ao passo em que a presença do artista, cujas dimensões são emprestadas ao recipiente submerso, permanece estática, submetida ao escoar do riacho. Em uma situação em que o artista e a matéria trabalhada parecem assumir a posição um do outro, são as águas correntes que, atritando o corpo de Penone, dão 


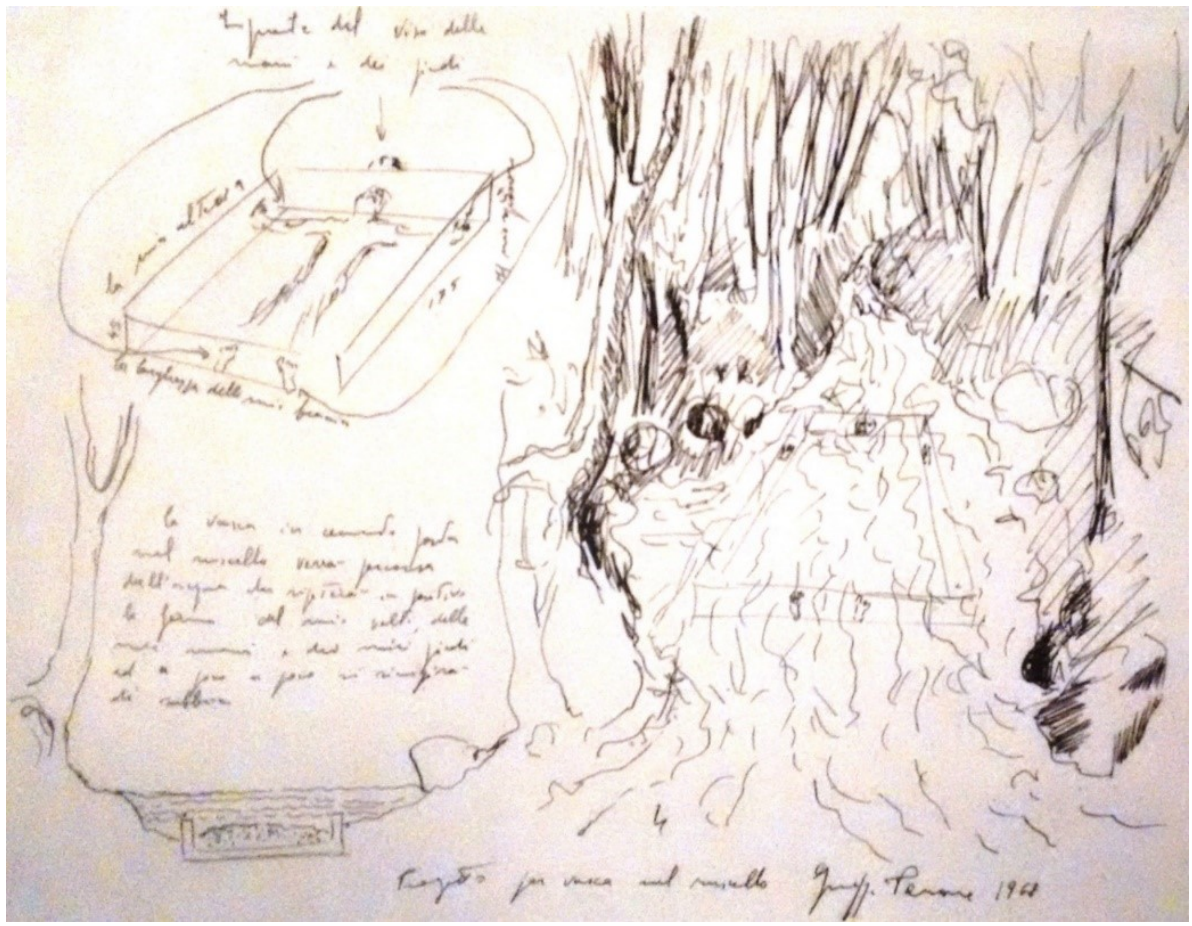

Fig. 1 - Giuseppe Penone, Projeto para banheira em riacho, 1968. Croqui (Fonte: MARANIELLO; WATKINS, 2009) 
Conhecer cada pedra, cada remanso, cada pequeno banco de areia

de um riacho, revisitá-Io a cada ano sentindoIhe 0 leito

para registrar as mudanças decorrentes das

chuvas, do gelo.

Nenhum elemento, nenhuma forma sua é ca-

sual.

Empalidecer as mãos por estar n'água para

ser,

ao menos uma vez, uma parte do rio.

(PENONE, 2009, p. 156, tradução nossa)

Penone explora, nesse trabalho, o registro pela escultura de movimentos sempre fluídos, inextinguíveis. Em um gesto que remete à "fossilização de fluxos contínuos" (PENONE, 2012), ele propõe a adesão de seu corpo, cujo volume ocupa um espaço mensurável, à dimensão imensurável da natureza. Ao criar Alpes marítimos (1968), Penone intervém no leito do pequeno córrego: com as formas de seu corpo submerso, altera a batimetria, insere altos relevos, fornece um conjunto de ondulações submersas que se assemelham a montanhas subaquáticas. O corpo do artista, tal qual as pedras e os pequenos bancos de areia existentes no leito, é metaforica- mente colocado sob a ação transformativa incessante do riacho (Fig. 2).

Imersas no pequeno rio, as pedras, muito possivelmente, se tornarão grãos de areia e estes serão cada vez menores à medida que desbastados pelo fluxo contínuo d'água. O limite que permite a diferenciação entre os elementos, portanto, é incerto. Se Penone, em Alpes marítimos, os reúne de maneira paritária à sua própria materialidade sob as águas - seu corpo, aparentemente, não apresenta qualquer protagonismo em relação aos seixos e demais elementos materiais erodidos pelo riacho -, no pequeno texto que o artista escreve a propósito dessa experiência, por sua vez, a equivalência entre as matérias é fortemente ressaltada. Embora o artista não esteja, naturalmente, no recipiente submerso, sua presença sob as águas é intuída em comum existência junto às pequenas pedras e grãos de areia (Fig. 3). A possibilidade de revisitação de tempos em tempos do leito do riacho pode ser compreendida como um desejo de aproximar a ordem temporal humana à temporalidade inestimável da natureza. 


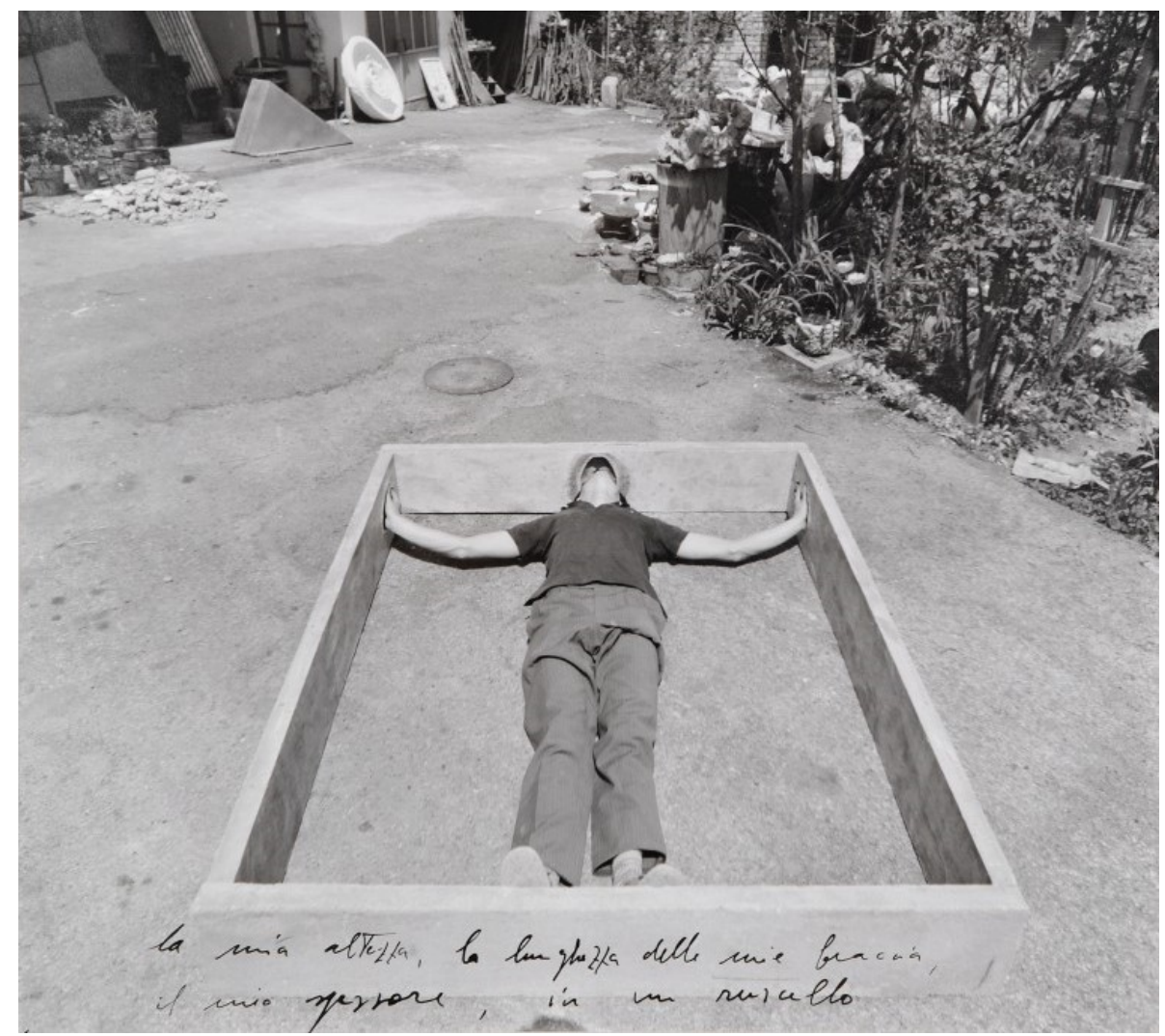

Fig. 2 - Giuseppe Penone, Alpes marítimos - a minha altura, o comprimento de meus braços, a minha espessura em um riacho, 1968. Registro fotográfico de execução da obra (Fonte: MARANIELLO; WATKINS, 2009) 


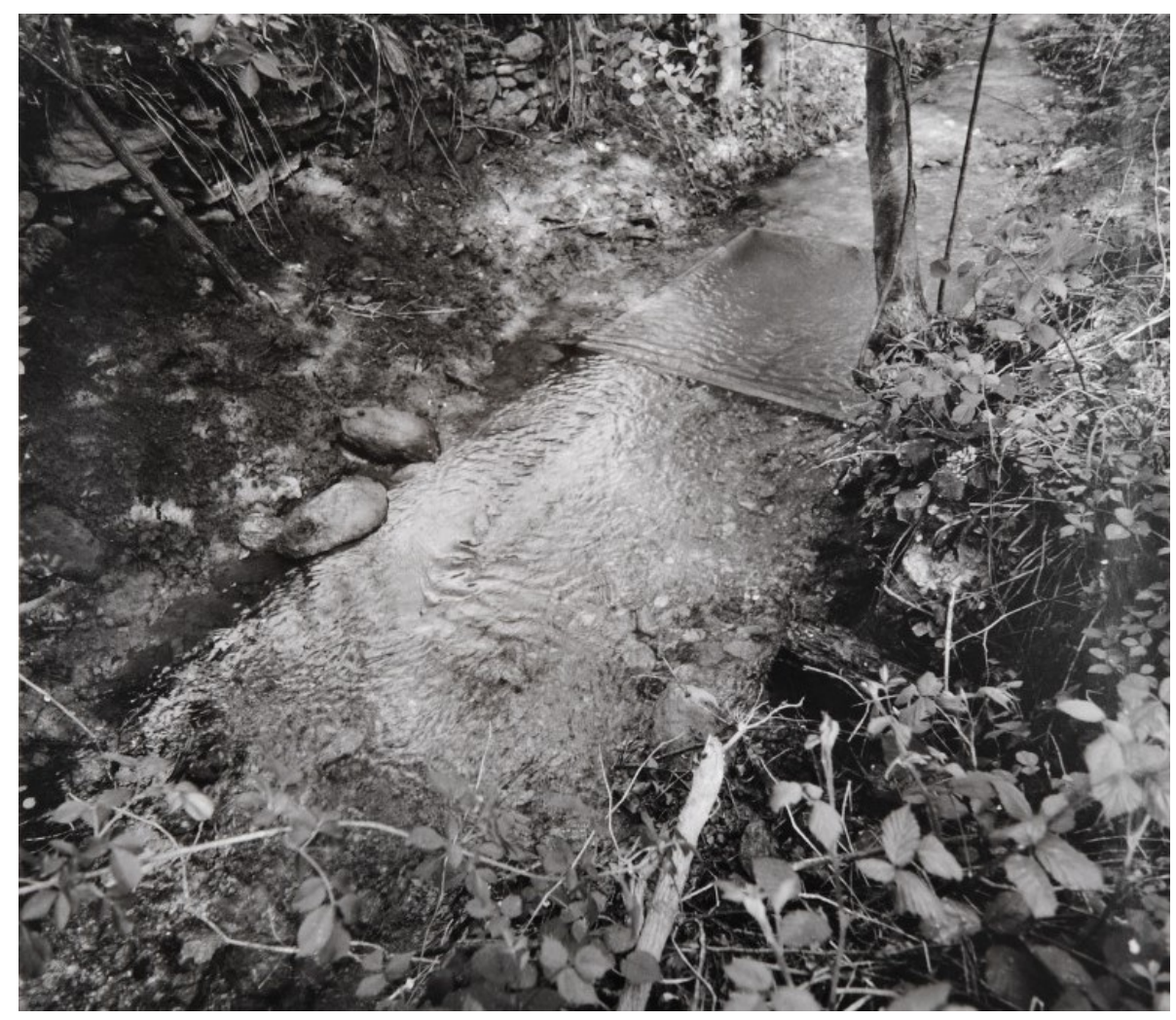

Fig. 3 - Giuseppe Penone, Alpes marítimos - a minha altura, o comprimento de meus braços, a minha espessura em um riacho, 1968. Registro fotográfico da obra (Fonte: MARANIELLO; WATKINS, 2009) 
O recipiente proposto por Penone certamente não corresponde, pois, a uma caixa de inspeção objetivamente colocada para aferições periódicas das condições d'água ou dos minerais. Trata-se de assumir a erosão enquanto ato fundamental de uma escultura telúrica, o qual não prevê a conclusão, em objeto escultórico, da matéria esculpida. Na realidade sempre inconclusa da Terra, não observamos senão as manifestações sensíveis dos elementos da natureza em sua constante interação. Vai daí o interesse de Penone em estar dentro do riacho, participando dele para registrar-lhe as mudanças decorrentes das chuvas, do gelo.

Há uma dimensão imaginativa associada às águas correntes que vem à tona em $\mathrm{A} /$ pes Marítimos. Com efeito, trata-se de uma escultura metafórica cuja existência é intuída sob as águas. Talvez apenas a materialidade do recipiente, cujo processo de construção fora também registrado em fotografia, seja um dado plenamente conhecido. No mais, a escultura apenas insinuase, em condições imaginárias, sob o brilho da superfície d'água. Sem recorrer à literalidade da forma escultórica tradicional, Penone a subverte poeticamente, tornan- do visíveis as formas inerentemente invisíveis do leito do córrego. Por elaborar, nessa obra, uma imagem poética fortemente associada às águas correntes, cabe recorrer aos seguintes dizeres do filósofo Gaston Bachelard a propósito da imaginação material dos rios:

\section{Fresca e clara é também a canção do rio. Re- almente, 0 rumor das águas assume com toda naturalidade as metáforas do frescor e da cla- ridade. As águas risonhas, os riachos irônicos, as cascatas ruidosamente alegres encontram- se nas mais variadas paisagens literárias. Esses risos, esses chilreios são, ao que parece, a lin- guagem pueril da Natureza. No riacho quem fala é a Natureza criança. (BACHELARD, 2013, p. 35)}

Os rios remontam, para quem se permite imaginar sua existência sempre fluída, sempre corrente, às condições mais primitivas da natureza. Ao contrário das águas calmas, que refletem na Terra as formas do céu, quando cristalinas, ou que levam ao mais profundo torpor quando turvas, barrentas, segundo Bachelard, as águas correntes, por sua vez, atualizam incessantemente a jovialidade da natureza. São elas que esculpiram e continuam a escul- 
pir, em seu fluxo contínuo, as formas da Terra. Os pequenos regatos, em seu curso tortuoso, mantêm na natureza o frescor do início de sua existência; o escoar alegre das águas preserva sempre vigente às suas margens o instante inaugural de suas formas. É nesse fluxo sempre inaugural que Penone imerge em Alpes Marítimos. O espaço, nessa obra, é abordado pelo artista enquanto a dimensão em que se dá o modo mais ancestral de escultura - o embate entre a água e a rocha, o atrito entre as matérias pelo qual são esculpidas as formas da natureza.

Se em Alpes marítimos, Penone abordou a relação entre seu corpo e a natureza, trabalhando, entre outros aspectos, a imaginação das águas correntes, dez anos mais tarde o interesse central de outra obra do artista se voltaria ao fluxo do ar, à ocorrência de um sopro enquanto potência escultórica. Em Sopro de folhas (1979), Penone reúne uma quantidade razoável de folhas secas, as quais ele organiza em uma grande pilha. Deixando que seu corpo caia sobre as folhas, ele deforma a piIha anterior, imprimindo nela suas próprias formas. Por fim, com o corpo deitado de bruços e o rosto repousado sobre as folhas, Penone expira pela boca, emitindo um leve sopro (Fig. 4).

Ao organizar as folhas secas na forma de uma pilha, Penone prepara a matéria que será por ele modelada. Trata-se de uma matéria maleável: se, quando isoladas, as folhas secas se quebram facilmente, quando dispostas aos montes, por outro lado, conservam com as ínfimas porções de ar presentes entre elas a capacidade plástica de amoldar-se quando comprimidas. Ao proceder desse modo, Penone reforça o interesse de sua arte pelas forças segundo as quais se arranjam as formas da natureza - forças sempre misteriosas, sempre estranhas à condição humana. Tal interesse pode ser confirmado pelos seguintes versos de Penone a propósito de Sopro de folhas: 


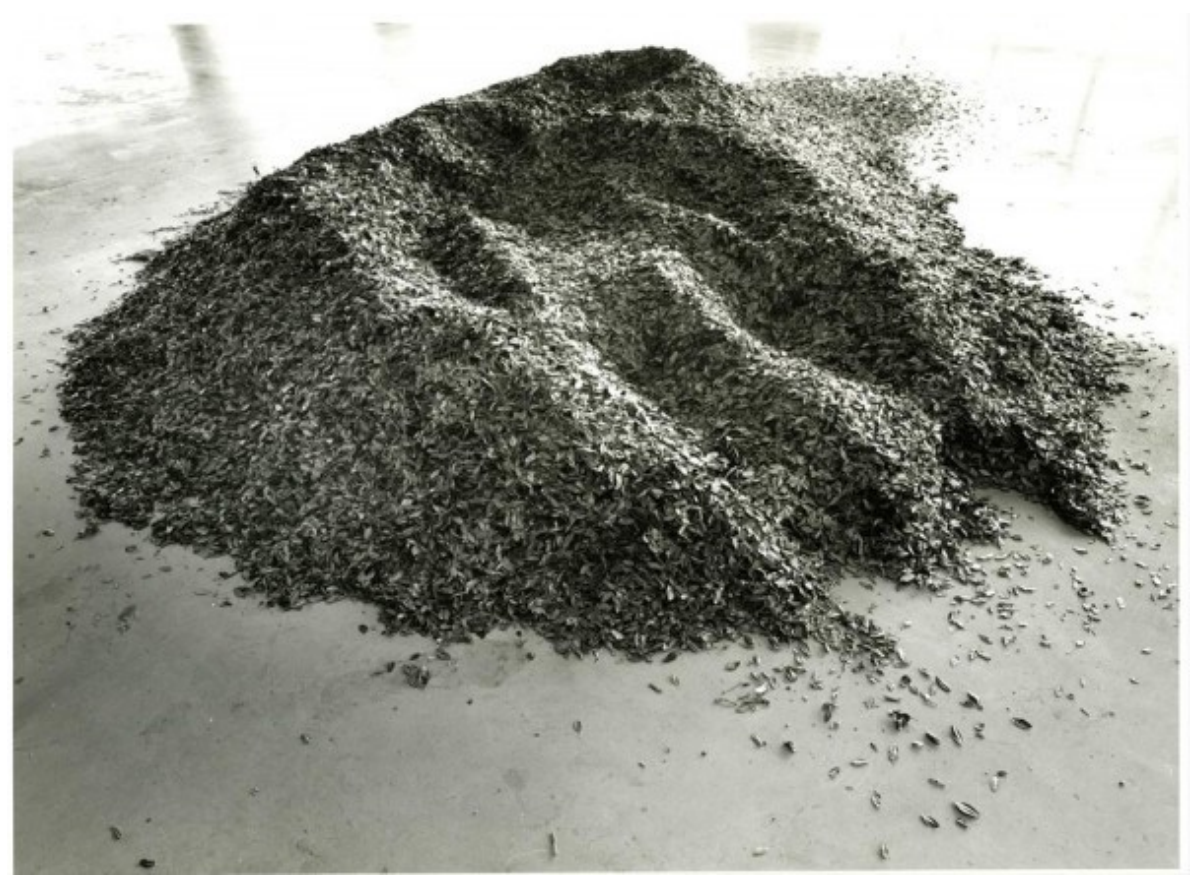

Fig. 4 - Giuseppe Penone, Sopro de folhas, 1979. Registro fotográfico da obra (Fonte: MARANIELLO; WATKINS, 2009) 
A princípio da cura da selva virgem,

onde 0 sopro incide nas folhas

em contínuo fluxo sob o impulso da lógica do vento,

tenta-se ocupar os espaços silenciosamente rastejantes, negativos privilegiados

da forma em movimento que, no que se repe-

te, tende a esculpir-se.

As pálpebras fechadas, o corpo turvo reclina-

se ao antigo leito;

a nuca se afoga na folhagem

e, aberta a boca, a respiração afunda no monte de folhas.

[...]

(PENONE, 2009, p. 215, tradução nossa)

O artista remonta às origens da relação entre o homem e a natureza, a momentos que precederam o cultivo da Terra. O texto supracitado, muito imagético do ponto de vista espacial, evoca uma selva escura, na qual o homem está sujeito às implicações das forças veladas da natureza. Há certa tensão que faz com que o deslocamento do corpo deva ser rasteiro e silencioso. O sopro que flui pela selva, sob a lógica indecifrável do vento, parece premer o homem a encontrar um pequeno nicho onde possa acolher-se. A imagem do abrigo pode ser depreendida da referência ao "antigo leito", que nada mais é que a concavidade privilegiada pela ação repetitiva do peso do corpo sobre as folhas. Uma vez abrigado da hostilidade do vento, e ainda imerso na natureza, o corpo todo repousa, o homem inaugura sua morada no abrigo de folhas moldado a partir de suas próprias formas. O negativo do corpo sobre as folhas, evocando a noção de abrigo, de acolhimento, em muito se assemelha à imagem do ninho que, nos dizeres de Gaston Bachelard, "é precário e, no entanto, desencadeia em nós um devaneio de segurança. [...] Assim, contemplando o ninho, estamos na origem de uma confiança no mundo, recebemos um aceno de confiança, um apelo à confiança cósmica" (BACHELARD, 2008, p. 115).

O espaço criado por Penone em Sopro de folhas, assim, evoca a imagem arquetípica do abrigo ancestral, permitindo à obra lançar-se às formas originárias pelas quais o homem habita a Terra. A dimensão cósmica que há nesse trabalho, na concavidade decorrente do peso e das formas do corpo do artista, coloca em jogo, a um só tempo, a lógica do vento que espalha as folhas secas e o leve sopro da boca de quem se deita sobre elas. Se, segundo 
Penone (2012), ao respirarmos, lançamos no espaço um volume de ar que já constitui, em si, uma forma de escultura, o sopro, tanto quanto o vento que derrubou as folhas ou o peso do corpo que as compactou, deve ser considerado, em sua obra, como um procedimento escultórico. A essa altura, cabe recorrer a outro fragmento do poema de Penone a propósito do Sopro de folhas, no qual ele caracteriza as folhas como

\section{[...]}

\section{Elementos formados no ar e pelo ar,} pelo vento, transportadas pelo vento. Recriadas pela mão do homem repetem os contornos, os refluxos, os pequenos vórtices, a presença instável do vento.

Para repetir 0 vento se refazem as folhas. (PENONE, 2009, p. 215, tradução nossa)

Com efeito, o sopro coloca em atrito a existência invisível do ar à das outras matérias que nos cercam. Trata-se de um fluxo, é matéria em deslocamento que, embora não possamos ver, nos chega aos ouvidos enquanto som ou sentimos na pe-

le enquanto arrepio. Enquanto procedimento escultórico, o sopro é trabalhado por Penone como uma das possibilidades de troca entre o interno e o externo do corpo. Essa mesma troca está presente, em Sopro de folhas, também, na relação entre o cheio do corpo e o vazio decalcado por ele sobre as folhas secas. Em outras palavras, o peso do corpo e o sopro que ele emite, enquanto forças interiores que se lançam para o exterior, são ações inerentes a um modo atávico de se fazer esculturas.

A investigação de Penone a respeito dos diferentes materiais e das inúmeras possibilidades de, a partir do contato direto com seu corpo, trabalhá-los em obras de caráter espacial, permanece reconhecível após a finalização do processo de criação. Com efeito, a experiência do espaço transformado a partir de suas obras corresponde à revelação das investigações pelas quais elas foram concebidas. Na obra Bifurcação (1987), Penone comprime sua mão espalmada contra uma camada de argila aplicada nas reentrâncias de um tronco de árvore previamente escavado. $\mathrm{O}$ encaixe preciso entre as formas de sua mão e o tronco é mediado, justamente, 
pela plasticidade da argila, receptiva tanto às formas da força manual que a comprime quanto à rugosidade da casca do tronco sobre o qual fora aplicada (Fig. 5).

Ao imprimir baixos relevos no tronco aberto, Giuseppe Penone cria nervuras que remontam, a um só tempo, à rede de vasos condutores de seiva da árvore, a um conjunto de pequenos cursos d'água convergentes em um rio principal e ao negativo de sua mão. Associados a essa mesma forma esculpida, o fluxo d'água pela terra, a verticalidade da árvore e as bifurcações dos dedos humanos compartilham do espaço aberto por Penone na madeira do tronco. Mais do que isso, no espaço criado em Bifurcação, esses diversos elementos circulam em um único fluxo, confundindo-se mutuamente. Após concluir a modelagem do baixo relevo sobre a argila, Penone registra em fotografia o escoar d'água pelos canais esculpidos (Fig. 6).

A forma obtida por Penone em Bifurcação é antes apreendida como espaço do que como objeto formal. Trata-se, afinal, das concavidades decorrentes das formas curvas de sua mão. Como quem cria um molde em massa ou argila, Giuseppe Pe- none faz uma obra que parece convocar a presença de outras matérias em seu interior. Os vales configurados pelos dedos e a planura da mão espalmada permitem que se intua seu preenchimento pelas substâncias mais diversas. Afora as imagens do fluxo aquoso pela obra, registradas em fotografia, o artista exprime, em versos, os pequenos espaços de Bifurcação como uma rede de vasos condutores que tendem à verticalidade, evocada tanto pela imagem da árvore quanto pelo corpo humano, permitindo que assomem em direção ao céu as substâncias que emergem das profundidades da Terra. 


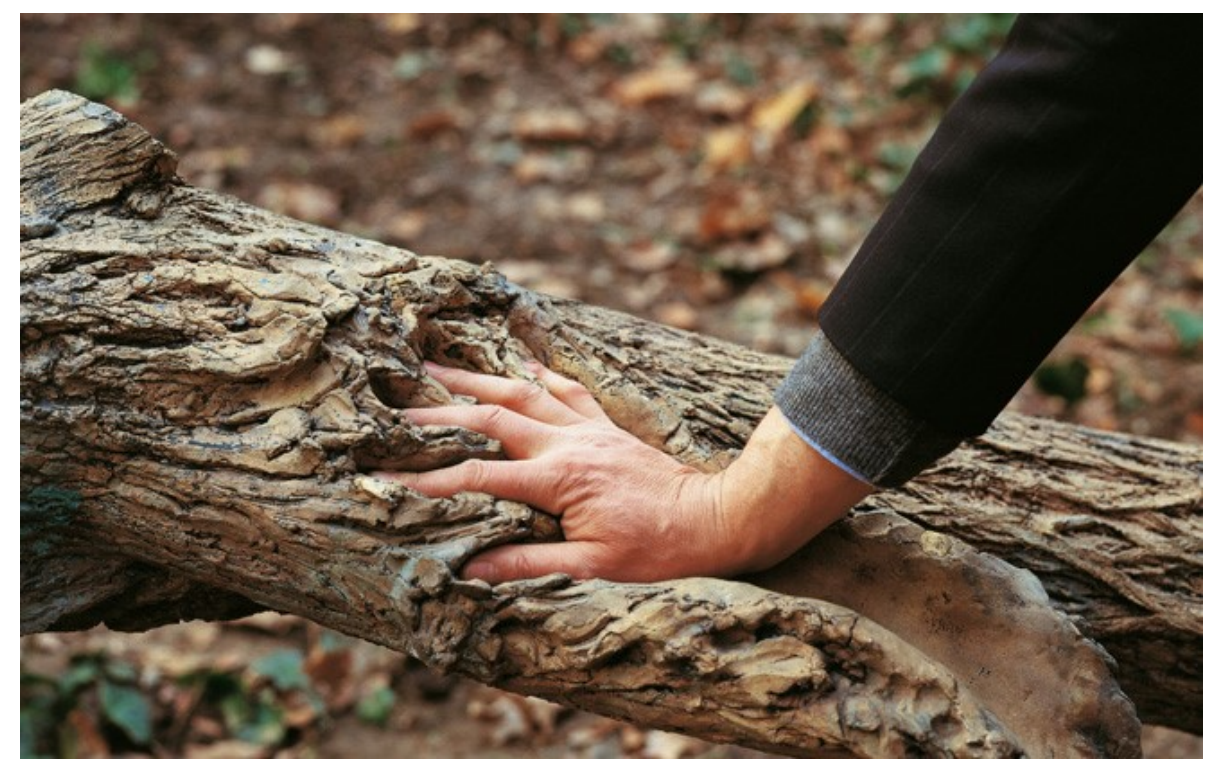

Fig. 5 - Giuseppe Penone, Biforcazione, 1987. Registro fotográfico de execução da obra (Fonte: MARANIELLO; WATKINS, 2009) 


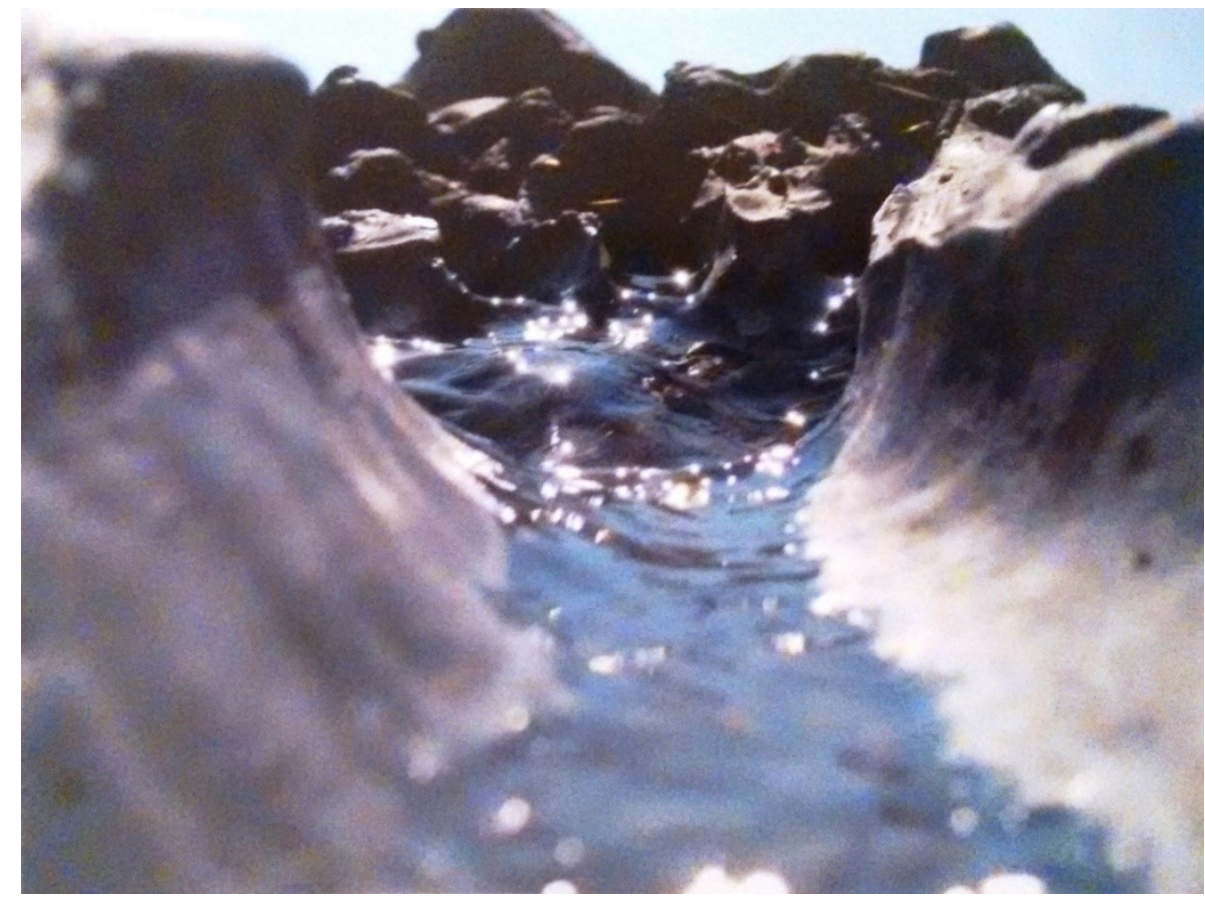

Fig. 6 - Giuseppe Penone, Biforcazione, 1987. Registro fotográfico da obra (Fonte: MARANIELLO; WATKINS, 2009) 
A água que percorre o subsolo, que conhece os segredos do subsolo.

0 misterioso rumor d'água que caindo em um poço produz

um movimento circular. 0 cilindro de ar que penetra na terra.

As cinco fontes dos dedos que confluem na palma da mão

para depois escorrerem juntas no braço. A verticalidade d'água expressa pelos vegetais. As bifurcações das árvores que a nós parecem muito intimamente humanas. As bifurcações dos dedos

e as confluências dos rios. As bifurcações dos dedos da mão,

pelo seu movimento no espaço, formam os ramos, as raízes

e pela sucessão de gestos nos mesmos pontos, constroem os galhos e 0 tronco do vegetal. A paisagem do bosque é o gesto da escultura. (PENONE, 2009, p. 149, tradução nossa)

Ao afundar sua mão contra a argila, como quem, pela primeira vez, afirma os pés ao caminhar por um bosque, Penone deixa uma pegada, uma marca de sua presença sobre a Terra. Esse gesto ancestral, em torno do qual orbita a poética da obra, comparece de modo integral no espaço esculpido. Com isso, no momento em que se dá a experiência da obra, é sempre atualizado o instante de sua elaboração, o momento exato em que os dedos do artista, ao serem calcados na argila, dão forma aos vãos que há entre eles. A partir desse gesto, cujo movimento dá origem às estruturas de uma árvore, Penone remonta a um dos mais fortes arquétipos do crescimento, da estabilidade, da verticalidade. Ao mesmo tempo em que se enterra, procurando as profundezas mais escuras, a árvore lança seus ramos mais etéreos aos céus. Todo o sonho de fluxos, de circulação de líquidos, encontra na árvore uma imagem muito potente: as raízes, como rios subterrâneos, bebem a água que há na Terra para lançá-la em um movimento de ascensão em direção aos seus ramos mais etéreos. Para abordar certos aspectos da imagem dos vegetais trabalhada por Penone, tais como o emaranhado de raízes, a originalidade da árvore enquanto imagem do crescimento, do movimento ascendente, vale recorrer aos seguintes dizeres de Bachelard a propósito da árvore:

A raiz domina o obstáculo contornando-0. Ela insinua suas verdades; estabiliza o ser por sua multiplicidade. [...] Ao lado das raízes, logo sonhamos a Terra inteira como se ela fosse um nó de raízes, como se apenas as raízes pudes-

Arthur Simões Caetano Cabral, Entre a Terra e o corpo: a experiência da natureza na obra de Giuseppe Penone. 
sem assegurar a síntese da Terra. Depois, é preciso surgir: toda vida e toda vontade foram inicialmente uma árvore. A árvore foi o primeiro crescimento. (BACHELARD, 2003, p. 238)

A relação de estranhamento que há entre o homem e a Terra se concentra no espaço criado pela mão inscrita no tronco escavado, onde coexistem o movimento exato que deu origem à obra e sua experiência sensível. Ao emprestar a organicidade das formas de seu corpo a um espaço que é comum aos seres humanos, aos rios, às raízes e aos ramos das árvores, reconhecendo as formas desse espaço como um aspecto comum à condição humana e à natureza, Penone não se contrapõe, contudo, à relação de alteridade inerente à paisagem. Pelo contrário, ao identificar, nos versos que escreve, a impressão no espaço das bifurcações dos dedos com a construção dos galhos e do tronco de uma árvore, Penone reforça o mistério com que a natureza se mostra para nós. O artista coloca em jogo uma relação ambivalente: se, por um lado, compartilhamos em nosso corpo de muitas das formas que vemos à nossa volta, se "as bifurcações das árvores a nós parecem muito intimamente humanas", por outro lado, sendo "a paisagem do bosque o gesto da escultura" (PENONE, 2009, p. 149, tradução nossa), a natureza nunca se revela por completo, permanecendo irremediavelmente estranha para nós.

O percurso artístico de Giuseppe Penone o levou, em 2003, a explorar materiais e técnicas bastante diversos. Se em Bifurcação a questão central para o artista eram os fluxos compartilhados entre os rios, os homens, as árvores, em Pele de mármore (2003) é com a dimensão mineral da Terra que o corpo humano vem confundir-se. A partir de um conjunto expressivo de placas de mármore dispostas lado a lado sobre o piso de um jardim, Penone esculpe em baixo relevo as nervuras do material. Como procedimento, para tanto, ele seguiu os veios existentes, examinando atenciosamente pelo tato as regiões das placas que deveriam ser rebaixadas e as outras que, por serem mais resistentes, deveriam ser mantidas em sua condição original (Fig. 7). 


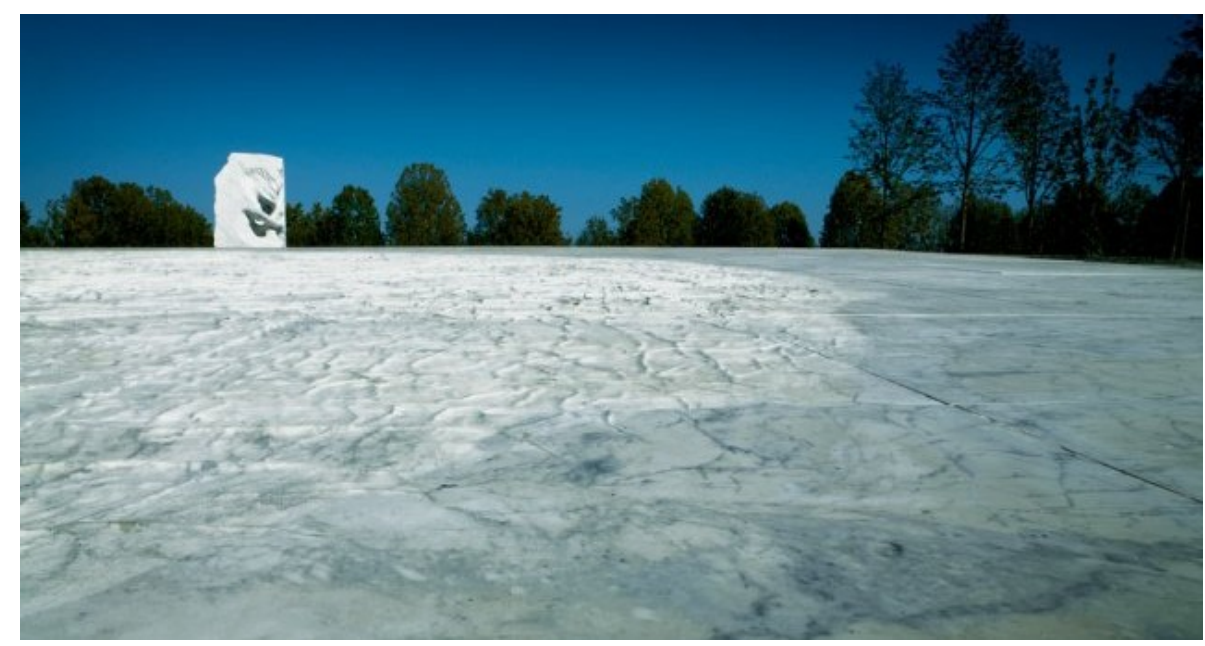

Fig. 7 - Giuseppe Penone, Pele de mármore, 2003. Registro fotográfico da obra (Fonte: MARANIELLO; WATKINS, 2009) 
Penone descobre as formas que definirão essa obra à medida que ele a elabora. Seu ponto de partida não é a definição do objeto a ser esculpido mediante o desbaste do mármore. Apenas um critério é dado a priori: a escultura deveria ser definida pela irregularidade quanto à resistência do material. As mãos assumem um papel de investigação, tateando a superfície de mármore e descobrindo, desse contato, os pontos que cederiam ao desbaste, distinguindo estes das regiões mais resistentes a serem mantidas intactas. Onde o material se mostra mais macio, a mão e o utensílio afundam, onde ele se faz mais resistente, surgem os altos relevos. $O$ gesto de esculpir é abordado em Pele de mármore como uma resposta à investigação dada pelo tato, como procedimento necessário para sublinhar a trama venosa existente nas superfícies de mármore examinadas pelas mãos do artista. No poema que escreve a propósito dessa obra, Penone evoca a relação entre a montanha e o bloco de mármore, relação entre exterior e interior cuja inversão permite revelar o conjunto de veias que permite a pulsação da montanha.
Uma pele de mármore branco, uma superfície coberta por pequenos sinais dos utensílios que indagam,

percorrem, escavam e sublinham suas veias, desvelando o tecido pulsante do monte.

0 interno e 0 externo.

0 interno reveste 0 externo, a matéria que há dentro do corpo usada para envolvê-lo.

A carne, os ossos, as veias da mão revestem a luva.

0 mármore reveste a mão, a pele e as veias, a envolve e a recobre de pó branco.

É a escultura de mármore, a pele de mármore. [...]

(PENONE, 2009, p. 291, tradução nossa)

A ideia de vitalidade da matéria é ressaltada já nos primeiros versos. O tecido pulsante do monte possui uma dimensão externa e outra interna. Penone propõe invertê-las, fazer com que a interioridade do mármore envolva o seu exterior. Como quem procede descarnando um corpo, $\mathrm{Pe}$ none decalca as nervuras do mármore, extraindo o interior do material sob a forma de um pó branco. A essa altura, as veias de sua mão, sua pele, se veem recobertas pelo interior particulado do mármore, que por sua vez fora extraído do monte. $\mathrm{Na}$ experiência do espaço cujo processo de elaboração corresponde a tão 
forte contato entre o corpo humano e a existência mineral da Terra reconhece-se, pois, um emaranhado de veias, rugosidades, dobras e reentrâncias absolutamente orgânicas (Fig. 8).

A forma esculpida é consequência, assim, da leitura tátil da superfície do mármore. O contato do corpo com a matéria tem papel principal na obra. Segundo comentário de Penone (2012), há uma ideia de reciprocidade nos confins dos corpos, onde se dão os escambos entre eles. Entre a pele das mãos que examinam e a pele do mármore que é examinado, o artista elabora, poeticamente, a imaginação do embate, do trabalho da Terra pelas mãos humanas. Para a abordagem dos devaneios da vontade do trabalho manual da matéria, vale recorrer, mais uma vez, ao pensamento de Gaston Bachelard. Em seu ensaio sobre a imaginação das forças, no qual um capítulo é inteiramente destinado ao rochedo, as forças minerais confundem-se aos esforços de mineração. Como em Pele de mármore, os seguintes dizeres demonstram a confusão de aspectos fisionômicos entre o homem e o rochedo por ele esculpido,
[...] um rochedo que recebe tão prodigioso esforço do homem já é homem também. E vejo-os enfrentarem-se. 0 rochedo explicita 0 esforço humano, é o belo complemento direto de um bíceps consciente de sua potência. (BACHELARD, 2013, p. 155) 


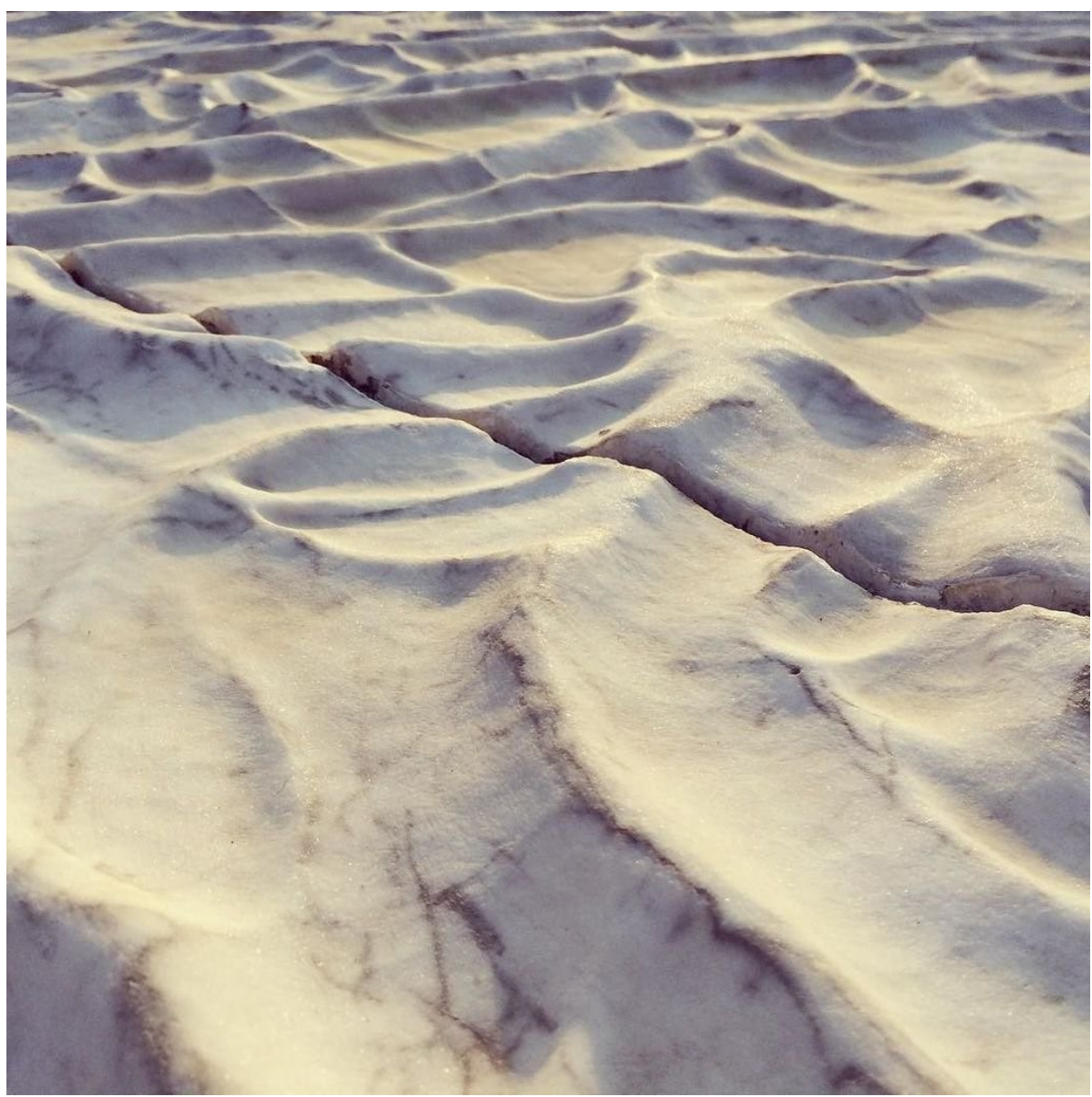

Fig. 8 - Giuseppe Penone, Pele de mármore, 2003. Registro fotográfico de detalhe da obra (Fonte: MARANIELLO; WATKINS, 2009) 


\section{Considerações finais}

$\mathrm{Na}$ impossibilidade de apresentar toda a produção de Giuseppe Penone, procurouse neste artigo percorrer um pequeno conjunto de suas obras com vistas a compreender a relação que nelas se estabelece entre o homem e a natureza. Sem procurar resolver o estranhamento inerente à condição humana ante à natureza, nos dizeres de Rilke, e sem tornar menos misteriosa a natureza para nós, nos dizeres de Carchia, Penone coloca não apenas o seu próprio corpo, como também experimenta suas obras em contato direto com a natureza. Nesse sentido, pode-se depreender que Penone assume a potência originária da natureza, em constante interação com seus gestos e com a materialidade de seu corpo, como força artística criadora elementar. Tal interação, por sua vez, assume expressão poética tanto in situ, em trabalhos tridimensionais cuja concepção supera e subverte os limites da relação escultórica objetiva, como também em verbo, em poemas que, para muito além de descrever objetivamente os processos e as obras escultóricas, inauguram novas imagens poéticas à superfície das palavras, valendo por si.
Além disso, é possível reconhecer a atualidade de sua obra e das questões centrais investigadas pelo artista na abordagem estética de outros modos possíveis de existência do homem em sua relação inextricável com a Terra, segundo os quais, notadamente, a materialidade da natureza e o fazer humano passariam a partilhar de um protagonismo eminentemente criador, estabelecido antes pela convergência harmônica de suas energias do que pela simples extração de materiais da natureza. Tais interações não apenas põem em questão a dicotomia convencionalmente estabelecida entre natureza e cultura como também sinalizam modos de produção alternativos aos modelos de exploração (e devastação) da Terra e das tentativas de controle pleno da natureza pelo fazer humano. Tornandose íntimo da existência dos mais diferentes elementos naturais mediante gestos escultóricos atávicos - respirar, comprimir com as mãos, deitar o corpo, tatear superfícies -, Penone investiga práticas e procedimentos atinentes à concepção da escultura na contemporaneidade, ao mesmo tempo em que aprofunda, em termos sensíveis, o que permanece invisível na paisagem e convida quem a experimenta a desvelamentos futuros. 


\section{Notas}

${ }^{1}$ Dentre muitas acepções possíveis, a ideia de paisagem é entendida pelo filósofo Rosario Assunto enquanto espaço finito, mas que se abre à infinitude. A paisagem corresponde, nesses termos, à espacialização da temporalidade da natureza, ritmo incomensurável ao qual se negam as grandes cidades industriais. A megalópole industrial, para o autor, é o espaço da não memória, dos prazos de validade constantemente vencidos e do tempo rigorosamente quantificado e consumido - o qual o autor denomina temporaneidade. Esse espaço, enquanto negação do infinito, opõese à temporalidade da natureza, cujo caráter é qualitativo: nessa temporalidade, o presente não é uma subtração do passado nem o futuro um acréscimo ao presente. Ao contrário do ser temporâneo, o ser temporal é o passado que compreende o presente e o futuro, em uma coexistência mútua e infinita das três esferas. De modo geral, nesses termos, entende-se o espaço da cidade industrial como o da negação de paisagem (ASSUNTO, 2011, p. 356).

\section{Referências}

ASSUNTO, Rosario. A paisagem e a estética. In. SERRÃO, Adriana Veríssimo (org.) Filosofia da Paisagem - uma antologia. Lisboa: Centro de Filosofia da Universidade de Lisboa, 2011.
BACHELARD, Gaston. A água e os sonhos: ensaio sobre a imaginação da matéria. Tradução de Antonio de Pádua Danesi. São Paulo: Martins Fontes, 2013.

BACHELARD, Gaston. A poética do espaço. Tradução de Antonio de Pádua Danesi.

São Paulo: Martins Fontes, 2008.

BACHELARD, Gaston. A Terra e os devaneios da vontade: Ensaio sobre a imaginação das forças. Tradução de Maria Ermantina de Almeida Prado Galvão. São Paulo: Martins Fontes, 2013.

BACHELARD, Gaston. A Terra e os devaneios do repouso: Ensaio sobre as imagens da intimidade. Tradução de Paulo Neves. São Paulo: Martins Fontes, 2003.

CARCHIA, Gianni. Per una filosofia del paesaggio. In: D’ANGELO, Paolo. (Org.) Estetica e paesaggio. Bolonha: Il Mulino, 2009.

KRAUSS, Rosalind. The Originality of the Avant-Garde and Other Modernist Myths. Cambridge; Londres: The MIT Press, 1978.

HEIDEGGER, Martin. A origem da obra de arte. São Paulo: Edições 70, 2010.

MARANIELLO, Gianfranco; WATKINS, Jonathan (Org). Giuseppe Penone - Scritti 1968-2008. Bolonha: Istituzione Galleria d'Arte Moderna - MAMbo, 2009. 
PENONE, Giuseppe. Incontro con Giuseppe Penone. Entrevista. Veneza: Museu Punta della Dogana, 2012. Disponível em

https://www. youtube. $\mathrm{com} /$ watch? $\mathrm{v}=\mathrm{wYd} 4$ 4hulEDE. Acesso em 28/5/2020.

RILKE, Rainer Maria. Del paesaggio / Introduzione. In: D'ANGELO, Paolo. (Org.) Estetica e paesaggio. Bolonha: Il Mulino, 2009.

TIBERGHIEN, Gilles. Land Art. In: CAUQUELIN, Anne. Arte contemporânea uma introdução. São Paulo: Martins, 2005. 